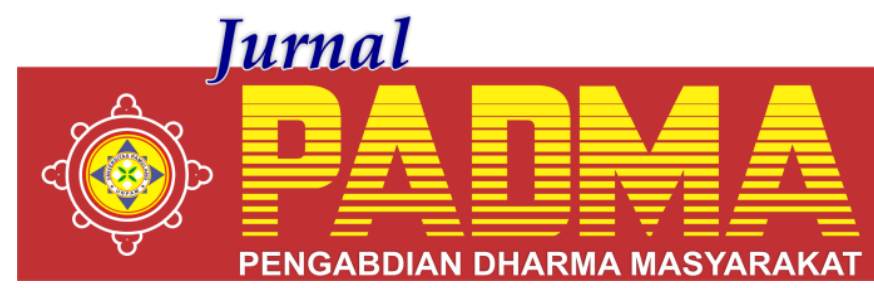

VOLUME 1, NOMOR 4, OKTOBER 2021

\title{
MANFAAT TEKNOLOGI SELAMA MASA PANDEMI
}

\author{
${ }^{1}$ Aries Yusril Ihza Mahendra, ${ }^{2}$ Esa Bagus Pratama, ${ }^{3}$ Erik Rudianto, ${ }^{4}$ Fatah Yasin, \\ ${ }^{5}$ Syalabi Abdillah, ${ }^{6 *}$ Bachtiar Arifudin Husain \\ Universitas Pamulang, Tangerang Selatan, Jawa Barat, Indonesia \\ *dosen01773@unpam.ac.id
}

\begin{abstract}
Abstrak
Banyak dari masyarakat menerima begitu saja teknologi informasi dan komunikasi modern yang bahkan tidak dapat diakses beberapa dekade lalu. Inovasi-inovasi teknologi informasi dan komunikasi ini, telah lama dianggap sebagai hal sepele, tidak penting, selama masa tenang kini menjadi sangat diperlukan dalam menghadapi pandemi COVID-19. Sekarang telah ada berbagai teknologi digital yang dapat digunakan untuk menambah dan meningkatkan strategi pekerjaan, pembelajaraan dan kesehatan masyarakat. Selama pandemi COVID-19, teknologi memainkan peran penting dalam menjaga kegiatan masyarakat tetap berfungsi pada saat Pembatasan Sosial Berskala Besar (PSBB). Disimpulkan bahwa masyarakat memanfaatkan saja teknologi informasi dan komunikasiuntuk tetap melaksanakan kegiatan karena fasilitas dan fitur dari saja teknologi informasi dan komunikasi yang memiliki keunggulan dan kemudahan untuk dipergunakan oleh berbagai kalangan masyarakat.
\end{abstract}

Kata Kunci: Teknologi Informasi, Komunikasi, Pandemi, Covid-19

\section{Abstract}

Many of the public take for granted modern information and communication technology that was not even accessible decades ago. These information and communication technology innovations, have long been regarded as trivial, unimportant, as long as calm is now indispensable in the face of the COVID-19 pandemic. There are now a variety of digital technologies that can be used to augment and enhance job, learning and public health strategies. During the COVID-19 pandemic, technology played an important role in keeping community activities functioning during large-scale social restrictions (PSBB). It was concluded that the public only utilizes information and communication technology to continue to carry out activities because of the facilities and features of information and communication technology that has advantages and conveniences to be used by various groups.

Keywords: Information Technology, Communication, Pandemic, Covid-19

\section{PENDAHULUAN}

Pada tahun ini terjadinya Pandemi skala global yang menyebar di berbagai negara, termasuk negara Indonesia juga tak luput dari dampak pandemi ini, khususnya para pelajar atau mahasiswa seperti kita dimana kegiatan belajar mengajar yang tadinya dilakkukan secara tatap muka berubah drastis menjadi daring atau online, oleh karena itu banyak pelajar yang belum terbiasa akan cara belajar seperti ini serta blum paham akan manfaat teknologi yang pada akhirnya menimbulkan beberapa aspek negatif, seperti kurangnya ilmu yang didapat, efektifitas pembelajaran menurun, antusias untuk belajar, bahkan menimbulkan rasa jenuh bagi pelajar karena metode pembelajaran daring.
Karena perubahan metode pembelajaran yang tiba - tiba ini banyak orang tua yang mengeluh karena dirasa sulit menyiapkan apa saja yang perlu disiapkan untuk kegiatan daring dan banyak juga masyarakat yang masih gaptek atau belum memahami teknologi akan hal baru ini. kurangnya informasi inilah yang menyebabkan masyarakat terutama orangtua murid mengalami kesulitan akan hal ini.

Oleh karena itu pada PKM kali ini, kami bertujuan untuk menyuluhkan atau memberikan informasi kepada masyarakat supaya bisa mengakses beberapa platform daring yang penting untuk pendidikan bagi Anak - anak mereka, dan juga memberikan pengarahan supaya pembelajaran daring 
dapat menghasilkan pemahaman belajar yang efektif serta memberikan pemahaman tentang manfaat teknologi.

\section{METODE}

Metode pelaksanaan pengabdian kepada masyarakat ini diawali dengan melakukan peninjauan lapangan dan koordinasi dengan mitra. Metode kegiatan ini adalah mendatangi dan memberikan pelatihan dan diskusi pentingnya Pembelajaran daring serta memberikan pembelajaran tentang manfaat teknologi dikala pandemi bagi para siswa/siswi pelajar. kami juga memberikan Presentasi tentang etika pada saat pembelajaran daring maupun memanfaatkan teknologi yang baik dan sopan.

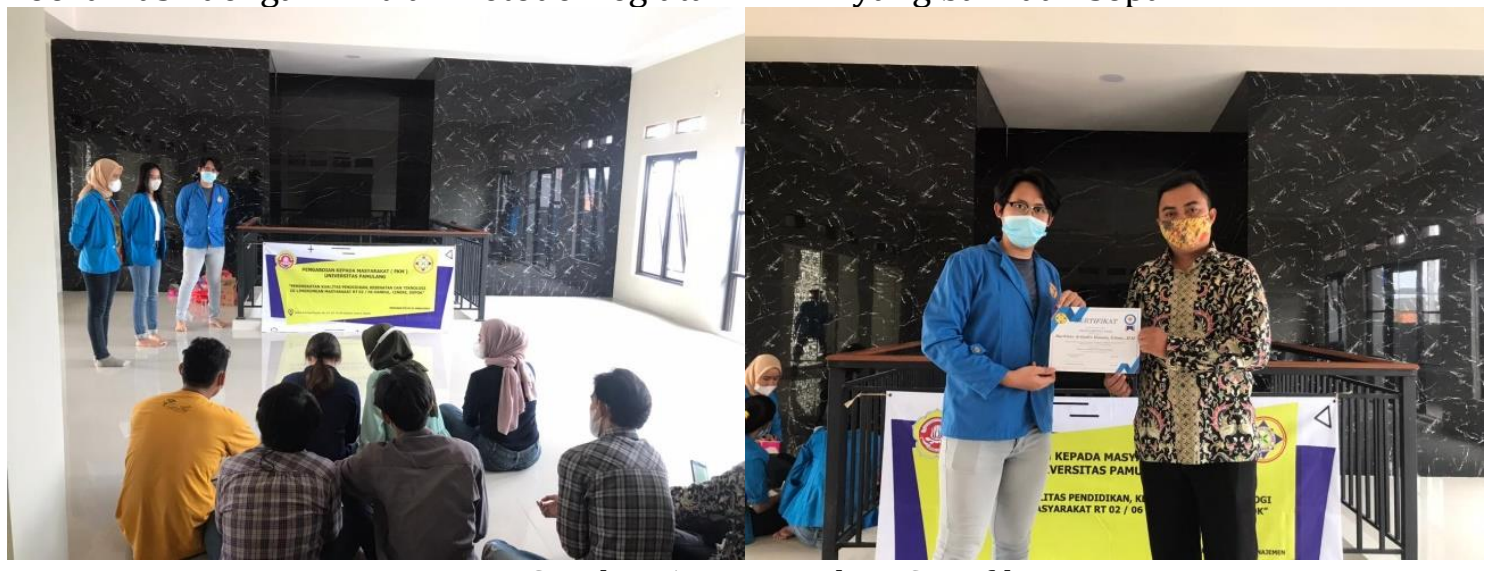

Gambar 1. Penyerahan Sertifikat

\section{HASIL DAN PEMBAHASAN}

Pada tahun ini terjadinya Pandemi skala global yang menyebar di berbagai negara, termasuk negara Indonesia juga tak luput dari dampak pandemi ini, khususnya para pelajar atau mahasiswa seperti kita dimana kegiatan belajar mengajar yang tadinya dilakkukan secara tatap muka berubah drastis menjadi daring atau online, oleh karena itu banyak pelajar yang belum terbiasa akan cara belajar seperti ini serta blum paham akan manfaat teknologi yang pada akhirnya menimbulkan beberapa aspek negatif, seperti kurangnya ilmu yang didapat, efektifitas pembelajaran menurun, antusias untuk belajar, bahkan menimbulkan rasa jenuh bagi pelajar karena metode pembelajaran daring.

Karena perubahan metode pembelajaran yang tiba - tiba ini banyak orang tua yang mengeluh karena dirasa sulit menyiapkan apa saja yang perlu disiapkan untuk kegiatan daring dan banyak juga masyarakat yang masih gaptek atau belum memahami teknologi akan hal baru ini. kurangnya informasi inilah yang menyebabkan masyarakat terutama orangtua murid mengalami kesulitan akan hal ini.
Oleh karena itu pada PKM kali ini, kami bertujuan untuk menyuluhkan atau memberikan informasi kepada masyarakat supaya bisa mengakses beberapa platform daring yang penting untuk pendidikan bagi Anak - anak mereka, dan juga memberikan pengarahan supaya pembelajaran daring dapat menghasilkan pemahaman belajar yang efektif serta memberikan pemahaman tentang manfaat teknologi.

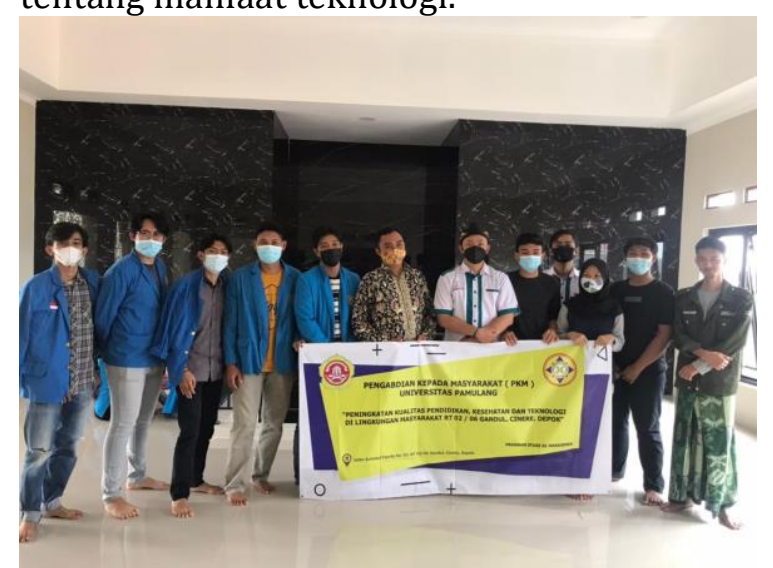

Gambar 2. Foto Bersama Peserta PKM

Sentuhan akademisi memberi warna dan sudut pandang yang berbeda. Dengan pemaparan dan diskusi serta memberi dorongan semangat masyarakat untuk mengetahui lebih banyak manfaat teknologi akan suatu Pembelajaran Daring dikala 
pandemi. Masyarakat bukan saja senang didatangi, namun lebih dari itu sebagai sebuah bentuk kegiatan dimana informasi sangat berperan penting bagi kehidupan sehari - hari dengan adanya kegiatan ini masyarakat jadi lebih tau dan diharapkan bisa memanfaatkan teknologi pembelajaran daring. Bagi civitas akademika (mahasiswa) khususnya dan bagi masyarakat umumnya. Dengan ada diskusi dan berdialog di masyarakat sekitar, menjadi solusi dari permasalahan pembelajaran daring $\mathrm{di}$ masyarakat.

\section{PENUTUP}

Setelah selesai ada baiknya kita mengulang atau merekap kembali apa yang telah kita dapat dari pembelajaran tersebut, supaya materi yang diberikan dapat kita pahami dan ingat dikala kita akan menghadapi ujian atau latihan yang akan datang, dan sebagai orang tua murid ada baiknya ibu/bapak sesekali memantau progres jalannya pembelajaran.

Saran dari kami agar pembelajaran lebih asik atau tidak jenuh pada saat daring ada baiknya dibawa santai tapi serius, santai bukan berarti malas ataupun berleha
- leha tapi dibawa enjoy jika disela pembelajaran bercanda melalui grup whatsapp kelas sehingga kalian bisa lebih akrab lagi.

\section{DAFTAR PUSTAKA}

Affandi, A., et al.. (2020). Optimization of MSMEs Empowerment in Facing Competition in the Global Market during the COVID-19 Pandemic Time. Systematic Reviews in Pharmacy, 11(11), 1506-1515.

Belawati, Tian dkk. (2019). Inovasi pembelajaran. Buku Materi Pokok TPEN4406. Jakarta: Universitas Terbuka

Rawi, R. D. P., \& Halina, N. (2019). Analisis Pengembangan Karir Yang Efisien Pada Badan Kepegawaian Dan Pengembangan Sumber Daya Manusia (BKPSDM) Kota Sorong.

Yuangga, K. D., et al. (2020). Pengembangan media dan strategi pembelajaran untuk mengatasi permasalahan pembelajaran jarak jauh di pandemi covid-19. JGK (Jurnal Guru Kita), 4(3), 51-58. 